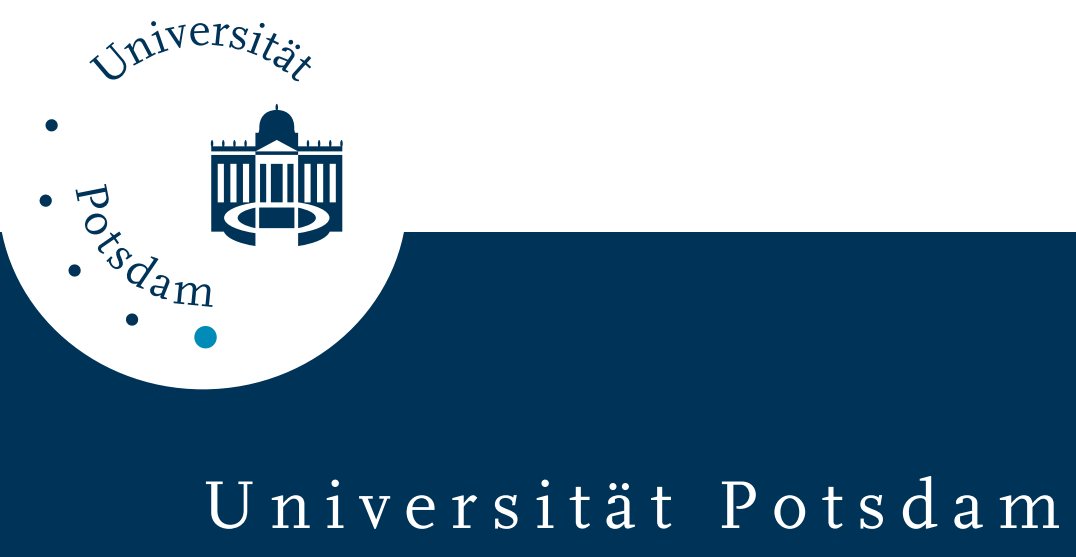

E. N. Oliveira Jr, Nour E. El Gueddari, Bruno M. Moerschbacher, Martin Peter, Telma Franco

\title{
Growth of phytopathogenic fungi in the presence of partially acetylated chitooligosaccharides
}

first published in:

Mycopathologia 166 (2008) 3, S. 163-174, DOI 10.1007/s11046-008-9125-0

Postprint published at the Institutional Repository of the Potsdam University: In: Postprints der Universität Potsdam

Mathematisch-Naturwissenschaftliche Reihe ; 105

http://opus.kobv.de/ubp/volltexte/2010/4264/

http://nbn-resolving.de/urn:nbn:de:kobv:517-opus-42646

Postprints der Universität Potsdam

Mathematisch-Naturwissenschaftliche Reihe ; 105 


\title{
Growth of Phytopathogenic Fungi in the Presence of Partially Acetylated Chitooligosaccharides
}

\author{
E. N. Oliveira Jr • Nour E. El Gueddari • \\ Bruno M. Moerschbacher · Martin G. Peter • \\ Telma T. Franco
}

\begin{abstract}
Four phytopathogenic fungi were cultivated up to six days in media containing chitooligosaccharide mixtures differing in average $\mathrm{DP}$ and $F_{\mathrm{A}}$. The three different mixtures were named Q3 (which contained oligosaccharides of DP2-DP10, with DP2-DP7 as main components), Q2 (which contained oligosaccharides of DP2-DP12, with DP2-DP10 as main components) and Q1 (which derived from Q2 and contained oligomers of DP5-DP8 with hexamer and a heptamer as the main components). The novel aspect of this work is the description of the effect of mixtures of oligosaccharides with different and known composition on fungal growth rates. The growth rate
\end{abstract}

E. N. Oliveira Jr · T. T. Franco $(\square)$

School of Chemical Engineering, State University

of Campinas, 6066, Campinas 13081-970, Brazil

e-mail: franco@feq.unicamp.br

N. E. El Gueddari - B. M. Moerschbacher Institute of Plant Biochemistry and Biotechnology, University of Muenster, Hindenburgplatz 55, 48143

Muenster, Germany

M. G. Peter

Institute of Chemistry, University of Potsdam, 14415 Potsdam, Germany of Alternaria alternata and Rhizopus stolonifer was initially inhibited by Q3 and Q2 at higher concentrations. Q1 had a growth stimulating effect on these two fungi. Growth of Botrytis cinerea was inhibited by Q3 and Q2, while Q1 had no effect on the growth of this fungus. Growth of Penicillium expansum was only slightly inhibited by higher concentrations of sample Q3, while Q2 and Q1 had no effect. The inhibition of growth rates or their resistance toward chitooligosaccharides correlated with the absence or presence of chitinolytic enzymes in the culture media, respectively.

Keywords Chitosan - Chitinase .

Fungi - Oligosaccharides · Phytopathogens

\begin{tabular}{|c|c|}
\hline \multicolumn{2}{|l|}{ Abbreviations } \\
\hline $\mathrm{A}=\mathrm{GlcNAc}$ & 2-Acetamido-2-deoxy-D-glucose \\
\hline $\mathrm{D}=\mathrm{GlcN}$ & 2-Amino-2-deoxy-D-glucose \\
\hline DHB & 2,5-Dihydroxybenzoic acid \\
\hline DP & Degree of polymerization \\
\hline$F_{\mathrm{A}}$ & $\begin{array}{l}\text { Mole fraction of GlcNAc residues in } \\
\text { chitosan or chitooligosaccharides }\end{array}$ \\
\hline GPC & Gel permeation chromatography \\
\hline MALDI TOF & Matrix assisted laser desorption \\
\hline MS & $\begin{array}{l}\text { ionization time of flight mass } \\
\text { spectrometry }\end{array}$ \\
\hline GR & Growth rate \\
\hline MEA & Malt extract agar \\
\hline PDA & Potato dextrose agar \\
\hline $\mathrm{CM}$ & Complete medium \\
\hline
\end{tabular}




\section{Introduction}

Chitin and chitosan are $\beta$-(1,4)-aminoglucopyranans composed of $N$-acetylglucosamine $(\mathrm{GlcNAc}=\mathrm{A})$ and glucosamine $(\mathrm{GlcN}=\mathrm{D})$ residues (for a review, see [1, 2]. After the discovery of an antifungal activity of chitosan by Allan and Hadwiger [3], the antimicrobial activity of the polysaccharide has been intensively studied $[4,5]$, e.g. for prolonging the shelf life of fruits and vegetables [6-12].

Much less is known on the biological activities of chitooligosaccharides toward microorganisms. Important parameters which could determine the bioactivity are, besides the $\mathrm{pH}$ of the culture medium, the DP and $F_{\mathrm{A}}$ of the oligosaccharides. However, bioassays were carried out mostly with mixtures of oligosaccharides of unknown composition. Thus, low-DP chitosans, in particular chitooligosaccharides with an average DP20, were more effective than high-DP chitosans in inhibiting mycelial growth of a variety of phytopathogenic and wood inhabiting fungi [4, 13, 14]. Oligosaccharides of DP9 and DP14 which had been prepared by nitrous acid depolymerization of chitosan were active against Leptographium procerum and Sphaeropsis sapinea, but not against Trichoderma harzianum, while oligomers of DP5 were inactive [15]. On the other hand, Fusarium solani was inhibited by chitooligosaccharides of DP $\geq 7$ [16] while oligomers of DP2-DP8 were not active against three Fusarium species [4].

The objective of this study was to investigate the activity of chitooligosaccharides, differing in average DP and in $F_{\mathrm{A}}$, in cultures of the phytopathogenic fungi Alternaria alternata, Botrytis cinerea, Penicillium expansum, and Rhizopus stolonifer, which are responsible for important economic losses in Brazilian fruit exports (citrus, strawberries, grapes, papaya, apples).

\section{Materials and Methods}

\section{Chitooligosaccharides}

Chitooligosaccharides were supplied by Genis ehf., Reykjavik, Iceland. They had been prepared by enzymatic degradation of chitosan. According to the supplier, the original oligosaccharide mixture used for preparation of Q3 had an average $M_{\mathrm{w}}$ of $696 \mathrm{Da}$ and an average $F_{\mathrm{A}}$ of 0.61 whereas the original chitosan used for preparation of Q2 had an average $M_{\mathrm{w}}$ of $1.133 \mathrm{Da}$ and an average $F_{\mathrm{A}}$ of 0.63 . The samples were dissolved in $0.05 \mathrm{M}$ ammonium acetate buffer, $\mathrm{pH} 4.2$, to give a concentration of ca. $12 \mathrm{mg} \times \mathrm{ml}^{-1}$. The solutions were ultrafiltrated through $0.8 \mu \mathrm{m}$ and $0.2 \mu \mathrm{m}$ cellulose acetate membranes (Schleicher \& Schuell) and a 3,000 Da cut-off membrane (Amicon). Finally, the filtrates were lyophilized. Q1 was obtained by GPC of Q2 on a Biogel P4 (fine grade, BioRad, München, Germany) column $(5 \mathrm{~cm}$ i.d. $\times 200 \mathrm{~cm})$, mobile phase $0.05 \mathrm{M}$ ammonium acetate buffer, adjusted with $0.23 \mathrm{M}$ acetic acid to $\mathrm{pH} 4.2$, flow rate $60 \mathrm{ml} \times \mathrm{h}^{-1}$; refractive index detector Shimadzu RID 6A. Fractions of $20 \mathrm{ml}$ were collected, and finally lyophilized. A fraction, containing oligosaccharides of DP5-DP8, was used for bioassay.

\section{Mass Spectrometry}

Samples containing ca. $100 \mu \mathrm{g}$ of oligosaccharides were mixed with $8 \mu \mathrm{l}$ of methanol/water (v/v 50/50). An aliquot of the solution $(0.5 \mu \mathrm{l})$ was mixed on the target with $0.5 \mu \mathrm{l}$ of a solution of DHB $\left(27 \mathrm{mg} \times \mathrm{ml}^{-1}\right)$ in $20 \%$ aqueous methanol, and the drop was dried under a gentle stream of air. Mass spectra were recorded on a Bruker Reflex II mass spectrometer (Bruker Daltonik, Bremen, Germany) in the positive ion mode. A nitrogen laser $(337 \mathrm{~nm}, 3 \mathrm{~ns}$ pulse width, $3 \mathrm{~Hz}$ ) was used. All spectra were measured in the reflector mode using external calibration by means of angiotensin II.

Microorganisms and Cultivation

A. alternata (CCT 2816), P. expansum (CCT 4680), and $R$. stolonifer (CCT 2002) were purchased from André Tosello Foundation Research and Technology (Campinas, Brasil). B. cinerea, an isolate from grape, was provided by the Department of Botany of the University of Munster. B. cinerea and P. expansum were cultured on potato dextrose agar (PDA) and in malt extract agar (MEA) supplemented with 2\% $(\mathrm{m} / \mathrm{v})$ each of glucose and peptone, while $R$. stolonifer and A. alternata were both cultured on MEA. In order to achieve sporulation, the fungi were incubated in Petri dishes $(\varnothing=9 \mathrm{~cm})$ for 8 days for A. alternata, B. cinerea, and $P$. expansum, and for 4 days for $R$. stolonifer at $25^{\circ} \mathrm{C}$ at $100 \mathrm{~cm}$ under $\mathrm{Hg}$ lamps with 
a $12 \mathrm{~h}$ photoperiod. Water suspensions of spores and mycelia were filtered through cotton. The concentration of spores was assessed using a hemocytometer (Fuchs-Rosenthal Hell Linie) under optic microscopy (magnification $400 \times$ ). The concentration of spores of $R$. stolonifer was adjusted to $10,000 \mathrm{ml}^{-1}$ and those of B. cinerea, A. alternata, and P. expansum to $20,000 \mathrm{ml}^{-1}$.

Bioassays

Complete medium (CM), pH4.3, was prepared as described by Pontecorvo [17], which contains approximately $6.2 \mathrm{~g} \times 1^{-1}$ carbon and $0.6 \mathrm{~g} \times 1^{-1}$ and nitrogen, by considering the contribution of yeast extract, peptone, casein and sucrose). Aliquots $(150 \mu \mathrm{l})$ of sterile $\mathrm{CM}$ containing the required volume of chitooligomer $\left(4 \mathrm{mg} \times \mathrm{ml}^{-1}\right)$ for dose response and sterile water were dispensed into wells of 96-well polystyrene microtiter plates $\left(\right.$ Roth $^{\circledR}$ ) containing either $10 \mu \mathrm{l}$ of a spore suspension of a test fungus or $10 \mu \mathrm{l}$ of sterile water (blanks). The plates were incubated at $25^{\circ} \mathrm{C}$ under agitation, 200 o.p.m (orbits per minute), for up to 3 days for $R$. stolonifer, 6 days for B. cinerea and A. alternata, and 5 days for $P$. expansum. Fungal growth was assessed by measuring the optical density of the culture media at $405 \mathrm{~nm} \mathrm{[18]} \mathrm{at} 24 \mathrm{~h}$ intervals for A. alternata, B. cinerea, and $P$. expansum and at $12 \mathrm{~h}$ intervals for $R$. stolonifer. Three independent experiments were carried out in triplicate each, and the data are reported as means \pm S.D. A standard curve was previously prepared to evaluate the correlation of absorbance values with dry weight of biomass. This calibration curve was found to be linear for the range between 0 and 4.0 for the fungi studied. According to Langvad [18], the absorbance measured in the microtiter plate reader is caused by light absorbance and light scattering.

Growth rate (GR) was calculated according to the following equation, and was expressed as $A_{405} \times$ day $\times \mathrm{h}^{-1}$ :

$\mathrm{GR}=\left(A_{t 2}-A_{t 1}\right) /\left(t_{2}-t_{1}\right)$

where $A$ is the measured absorbance value, $t_{1}$ is the initial time of the interval and $t_{2}$ is the time at end of the interval.

Growth rate inhibition and GR stimulation were calculated according to the following:
(\% ) $\mathrm{GR}_{\text {inhibition }}$ or $\mathrm{GR}_{\text {stimulation }}=\left(\mathrm{GR}_{\exp }\right.$

$\left.-\mathrm{GR}_{\text {control }}\right) / \mathrm{GR}_{\text {control }} \times 100$

where $\mathrm{GR}_{\exp }$ is the GR observed for the experiments which had oligosaccharides amended and $\mathrm{GR}_{\text {control }}$ is the value without any oligosaccharides (control experiments). When the value is negative, there is inhibition and when the value is positive, there is stimulation.

Degradation of Chitooligosaccharides

The spent media of cultures of fungi, containing initially $1,000 \mu \mathrm{g} \times \mathrm{ml}^{-1}$ of each oligosaccharide mixture, were analyzed after 3 and 6 days by MALDI TOF MS. An aliquot of the medium was mixed directly with methanol and the matrix, as detailed above.

Assay of Chitinolytic Enzyme Activity

Approximately $1 \mathrm{ml}$ of a water suspension of fungal spores was inoculated in $100 \mathrm{ml}$ of complete medium, placed into $250 \mathrm{ml}$ Erlenmeyer flasks and incubated at $26^{\circ} \mathrm{C}$ for 5 days under agitation at 120 o.p.m. The mycelial suspensions were filtered through Whatman paper no. 1 and the filtrate was lyophilized. The residue (ca. $1 \mathrm{~g}$ ) was dissolved in $4 \mathrm{ml}$ of ultra pure water (Milli-Q). Samples were desalted on prepacked Sephadex G-25 columns (PD-10, Amersham Biosciences, Uppsala, Sweden) pre-equilibrated with ultra pure water. The eluates were lyophilized, and the residues were resuspended in a minimal volume of water (ca. $50 \mu \mathrm{l})$. Aliquots of $20 \mu \mathrm{l}$ were spotted on filter paper (Amersham Biosciences, Uppsala, Sweden). Proteins showing chitinolytic activity were detected according to the method described by Trudel and Asselin [19] using poly-acrylamide gels containing $0.01 \%(\mathrm{w} / \mathrm{v})$ glycol chitin or chitosan $\left(F_{A} 0.22\right.$; DP1,383) in sodium acetate buffer (pH5.0). The filter papers containing the concentrated spent media were placed on the surface of the gel and incubated under humid atmosphere for $90 \mathrm{~min}$ at $37^{\circ} \mathrm{C}$. The paper was removed and a solution containing $0.01 \%(\mathrm{~m} / \mathrm{v})$ calcofluor M2R (Sigma-Aldrich, Steinheim, Germany) in $500 \mathrm{mM}$ Tris-HCl buffer (pH8.9) was added to the gels which were then incubated for $5 \mathrm{~min}$. The calcofluor solution was removed and the 
gel was rinsed overnight in distilled water. Lytic zones were visualized by the decrease of fluorescence under UV light.

\section{Results and Discussion}

\section{Characterization of Chitooligosaccharides}

For description of chitooligosaccharides, a one-letter short notation, i.e. A for GlcNAc and D for GlcN has been introduced and used since then [20-23]. Enzymatic depolimerization of chitosan gives always rather complex mixtures of oligomers (those differ in the number of sugar residues or DP), homologs (those differ in the number of $N$-acetyl groups or $F_{\mathrm{A}}$ ), and isomers (those differ in the sequence of $\mathrm{D}$ and $\mathrm{A}$ monomers). Separation of individual isomers is a formidable task which has, to our knowledge, not yet been achieved. Sequencing of components present in isomeric mixtures has been described so far only in few papers [20-22]. The novel aspect of this work here is the description of the effect of mixtures of oligosaccharides with different and known composition on fungal growth rates, and our aim is to assess the action of well-characterized oligosaccharides on the growth of the fungi.

The composition of the chitooligosaccharides, as revealed by MALDI TOF MS, is shown in Table 1 and Fig. 1. Sample Q3 contains oligomers of DP2-DP10 with A2, D1A2, D2A2 / D1A3, D2A3, D3A3, D4A3/D3A4, D4A4, D5A4, and D6A4 as the main homologue of each oligomer of a particular DP. Sample Q2 is distinguished from Q3 by the content of higher oligomers of DP up to 12 and by a relatively higher $F_{\mathrm{A}}$, as revealed by comparison of the relative intensities of the corresponding peaks of homologues, e.g. D2A2/D1A3/A4, or D2A3/D1A4, or D3A3/ D2A4, etc. (Table 1, Fig. 1a and b). The main oligosaccharides present in sample Q1 are the hexamer D2A4 and the heptamers D4A3 and D3A4.

\section{Bioassays}

The effects of chitooligosaccharides on the growth rates (GR) of A. alternata, B cinerea, P. expansum and $R$. stolonifer depended mostly on the concentrations amended to the culture media but also, in several cases, on the average degree of polymerization of the oligosaccharides. The results are shown in Table 2 and in Fig. 2. Within $24 \mathrm{~h}$ of incubation, the GR of A. alternata increased in the absence of chitooligosaccharides from nearly 0 up to $1 \mathrm{U}_{\mathrm{abs}} \times \mathrm{day}^{-1}$, reaching a plateau after 3 days. In the presence of chitooligosaccharides, the GR declined in the same time interval to $0.2-0.35 \mathrm{U}_{\mathrm{abs}} \times \mathrm{day}^{-1}$ when the concentrations of chitooligosaccharides varied between 200 and $1,000 \mu \mathrm{g} \times \mathrm{ml}^{-1}$ of Q3. After day 3 , the inhibition of higher Q3 concentrations was partially overcome (day 3 to day 5) and GR values even increased. However, at $100 \mu \mathrm{g} \times \mathrm{ml}^{-1}$ the GR was similar to that of the control, reaching the stationary phase at day 3 , probably due to lack of nutrition sources.

A similar behavior was also observed with Q2, where high GR were observed for the control and for the assay containing $100 \mu \mathrm{g} \times \mathrm{ml}^{-1}$ (GR 1.5 and $0.8 \mathrm{U}_{\mathrm{abs}} \times \mathrm{day}^{-1}$, respectively) whereas lower values (GR $0.3 \mathrm{U}_{\mathrm{abs}} \times \mathrm{day}^{-1}$ ) were found for higher concentrations. Between day 3 and day 5, GR increased from 0.75 to $1.25 \mathrm{U}_{\mathrm{abs}} \times$ day $^{-1}$ with higher concentrations of Q2 (200 to $1,000 \mu \mathrm{g} \times \mathrm{ml}^{-1}$ ) while the GR of the control and of the experiment containing $100 \mu \mathrm{g} \times \mathrm{ml}^{-1}$ Q2 remained stationary due to the lack of nutrition sources.

With sample Q1, the GR depended almost linearly on the concentration employed, varying from 0.7 to $1.5 \mathrm{U}_{\mathrm{abs}} \times$ day $^{-1}$. From day 3 to day 5, A. alternata apparently continued to efficiently use Q1, but after day 5, all GR were approximately zero (Fig. 2a). In conclusion, the GR of A. alternata were initially apparently inhibited by oligosaccharides of DP $>7$, but stimulated after degrading them to smaller fragments.

Figure $2 b$ shows the effect of the chitooligosaccharides on the growth of $B$. cinerea. With the same protocol as used for A. alternata, it was observed that the GR was inhibited by Q3 in a concentration dependent manner, i.e. the GR was $1.0 \mathrm{U}_{\mathrm{abs}} \times \mathrm{day}^{-1}$ for the control and ca. $0.25 \mathrm{U}_{\mathrm{abs}} \times \mathrm{day}^{-1}$ at $1,000 \mu \mathrm{g} \times \mathrm{ml}^{-1}$. Similar, but less pronounced effects on the GR of $B$. cinerea were observed with samples Q2 and Q1.

$P$. expansum was affected by $\mathrm{Q} 3$ in a different way than the other fungi, as the GR were similar to that of the control experiment for up to day $3\left(\mathrm{GR} 1.8 \mathrm{U}_{\mathrm{abs}} \times\right.$ day $^{-1}$ ) at concentrations $\leq 800 \mu \mathrm{g} \times \mathrm{ml}^{-1}$. An inhibition of growth (GR 1.1 $\mathrm{U}_{\mathrm{abs}} \times$ day $^{-1}$ ) was observed only at the highest concentration, i.e. $1,000 \mu \mathrm{g} \times \mathrm{ml}^{-1}$ 
Table 1 Composition of chitooligosaccharide mixtures as determined by MALDI TOF MS

\begin{tabular}{|c|c|c|c|c|c|c|c|}
\hline & \multicolumn{2}{|l|}{$\mathrm{Q}_{3}$} & \multicolumn{2}{|l|}{$\mathrm{Q}_{2}$} & \multicolumn{2}{|l|}{$\mathrm{Q}_{1}$} & \multirow{2}{*}{$\begin{array}{l}\text { Peak } \\
\text { assignment }\end{array}$} \\
\hline & $m / z$ & Rel. Intensity & $m / z$ & Rel. Intensity & $m / z$ & Rel. Intensity & \\
\hline \multirow[t]{2}{*}{ DP2 } & 447.20 & 86 & 447.22 & 100 & & & $\mathrm{~A} 2+\mathrm{Na}^{+}$ \\
\hline & 463.15 & 11 & 551.02 & & & & $\mathrm{~A} 2+\mathrm{K}^{+}$ \\
\hline \multirow[t]{2}{*}{ DP3 } & 608.22 & 100 & 608.26 & 96 & 608.55 & 3 & $\mathrm{D} 1 \mathrm{~A} 2+\mathrm{Na}^{+}$ \\
\hline & 650.24 & 13 & 650.26 & 79 & & & $\mathrm{~A} 3+\mathrm{Na}^{+}$ \\
\hline \multirow[t]{3}{*}{ DP4 } & 769.27 & 32 & 769.31 & 26 & & & $\mathrm{D} 2 \mathrm{~A} 2+\mathrm{Na}^{+}$ \\
\hline & 811.30 & 49 & 811.32 & 91 & & & $\mathrm{D} 1 \mathrm{~A} 3+\mathrm{Na}^{+}$ \\
\hline & & & 853.33 & 10 & & & $\mathrm{~A} 4+\mathrm{Na}^{+}$ \\
\hline \multirow[t]{5}{*}{ DP5 } & 930.36 & 9 & 930.39 & 12 & & & $\mathrm{D} 3 \mathrm{~A} 2+\mathrm{Na}^{+}$ \\
\hline & 972.38 & 42 & 972.40 & 71 & & & $\mathrm{D} 2 \mathrm{~A} 3+\mathrm{Na}^{+}$ \\
\hline & 988.36 & 3 & & & & & $\mathrm{D} 2 \mathrm{~A} 3+\mathrm{K}^{+}$ \\
\hline & 1014.40 & 3 & 1014.41 & 29 & 1014.48 & 13 & $\mathrm{D} 1 \mathrm{~A} 4+\mathrm{Na}^{+}$ \\
\hline & & & & & 1056.47 & 6 & $\mathrm{~A} 5+\mathrm{Na}^{+}$ \\
\hline \multirow[t]{6}{*}{ DP6 } & 1091.44 & 7 & 1091.48 & 8 & & & $\mathrm{D} 4 \mathrm{~A} 2+\mathrm{Na}^{+}$ \\
\hline & 1133.47 & 24 & 1133.49 & 42 & 1133.53 & 12 & $\mathrm{D} 3 \mathrm{~A} 3+\mathrm{Na}^{+}$ \\
\hline & 1149.42 & 3 & & & & & $\mathrm{D} 3 \mathrm{~A} 3+\mathrm{K}^{+}$ \\
\hline & 1175.48 & 6 & 1175.50 & 50 & 1175.54 & 100 & $\mathrm{D} 2 \mathrm{~A} 4+\mathrm{Na}^{+}$ \\
\hline & & & & & 1191.18 & 6 & $\mathrm{D} 2 \mathrm{~A} 4+\mathrm{K}^{+}$ \\
\hline & & & 1217.52 & 6 & 1217.25 & 5 & $\mathrm{D} 1 \mathrm{~A} 5+\mathrm{Na}^{+}$ \\
\hline \multirow[t]{3}{*}{ DP7 } & 1294.52 & 10 & 1294.55 & 15 & 1294.56 & 24 & $\mathrm{D} 4 \mathrm{~A} 3+\mathrm{Na}^{+}$ \\
\hline & 1336.53 & 10 & 1336.55 & 36 & 1336.58 & 39 & $\mathrm{D} 3 \mathrm{~A} 4+\mathrm{Na}^{+}$ \\
\hline & & & 1378.57 & 12 & 1378.61 & 4 & $\mathrm{D} 2 \mathrm{~A} 5+\mathrm{Na}^{+}$ \\
\hline \multirow[t]{4}{*}{ DP8 } & 1455.57 & 3 & 1455.61 & 7 & 1455.59 & 5 & $\mathrm{D} 5 \mathrm{~A} 3+\mathrm{Na}^{+}$ \\
\hline & 1497.57 & 7 & 1497.60 & 18 & 1497.58 & 4 & $\mathrm{D} 4 \mathrm{~A} 4+\mathrm{Na}^{+}$ \\
\hline & 1539.59 & 2 & 1539.60 & 16 & & & $\mathrm{D} 3 \mathrm{~A} 5+\mathrm{Na}^{+}$ \\
\hline & & & 1581.61 & 3 & & & $\mathrm{D} 2 \mathrm{~A} 6+\mathrm{Na}^{+}$ \\
\hline \multirow[t]{4}{*}{ DP9 } & & & 1616.66 & 4 & & & $\mathrm{D} 6 \mathrm{~A} 3+\mathrm{Na}^{+}$ \\
\hline & 1658.63 & 5 & 1658.63 & 12 & & & $\mathrm{D} 5 \mathrm{~A} 4+\mathrm{Na}^{+}$ \\
\hline & 1700.66 & 2 & 1700.63 & 18 & & & $\mathrm{D} 4 \mathrm{~A} 5+\mathrm{Na}^{+}$ \\
\hline & & & 1742.65 & 5 & & & $\mathrm{D} 3 \mathrm{~A} 6+\mathrm{Na}^{+}$ \\
\hline \multirow[t]{5}{*}{ DP10 } & 1777.67 & 2 & 1777.62 & 3 & & & $\mathrm{D} 7 \mathrm{~A} 3+\mathrm{Na}^{+}$ \\
\hline & 1819.66 & 3 & 1819.64 & 6 & & & $\mathrm{D} 6 \mathrm{~A} 4+\mathrm{Na}^{+}$ \\
\hline & & & 1861.67 & 10 & & & $\mathrm{D} 5 \mathrm{~A} 5+\mathrm{Na}^{+}$ \\
\hline & & & 1903.67 & 6 & & & $\mathrm{D} 4 \mathrm{~A} 6+\mathrm{Na}^{+}$ \\
\hline & & & 1945.69 & 2 & & & $\mathrm{D} 3 \mathrm{~A} 7+\mathrm{Na}^{+}$ \\
\hline \multirow[t]{3}{*}{ DP11 } & & & 2022.72 & 5 & & & $\mathrm{D} 6 \mathrm{~A} 5+\mathrm{Na}^{+}$ \\
\hline & & & 2064.72 & 5 & & & $\mathrm{D} 5 \mathrm{~A} 6+\mathrm{Na}^{+}$ \\
\hline & & & 2106.69 & 2 & & & $\mathrm{D} 4 \mathrm{~A} 7+\mathrm{Na}^{+}$ \\
\hline \multirow[t]{2}{*}{ DP12 } & & & 2183.76 & 4 & & & $\mathrm{D} 7 \mathrm{~A} 5+\mathrm{Na}^{+}$ \\
\hline & & & 2225.76 & 5 & & & $\mathrm{D} 6 \mathrm{~A} 6+\mathrm{Na}^{+}$ \\
\hline
\end{tabular}

Note: main components are in boldface. Only peaks corresponding to oligosaccharides are listed; matrix peaks and unidentified components are not shown 

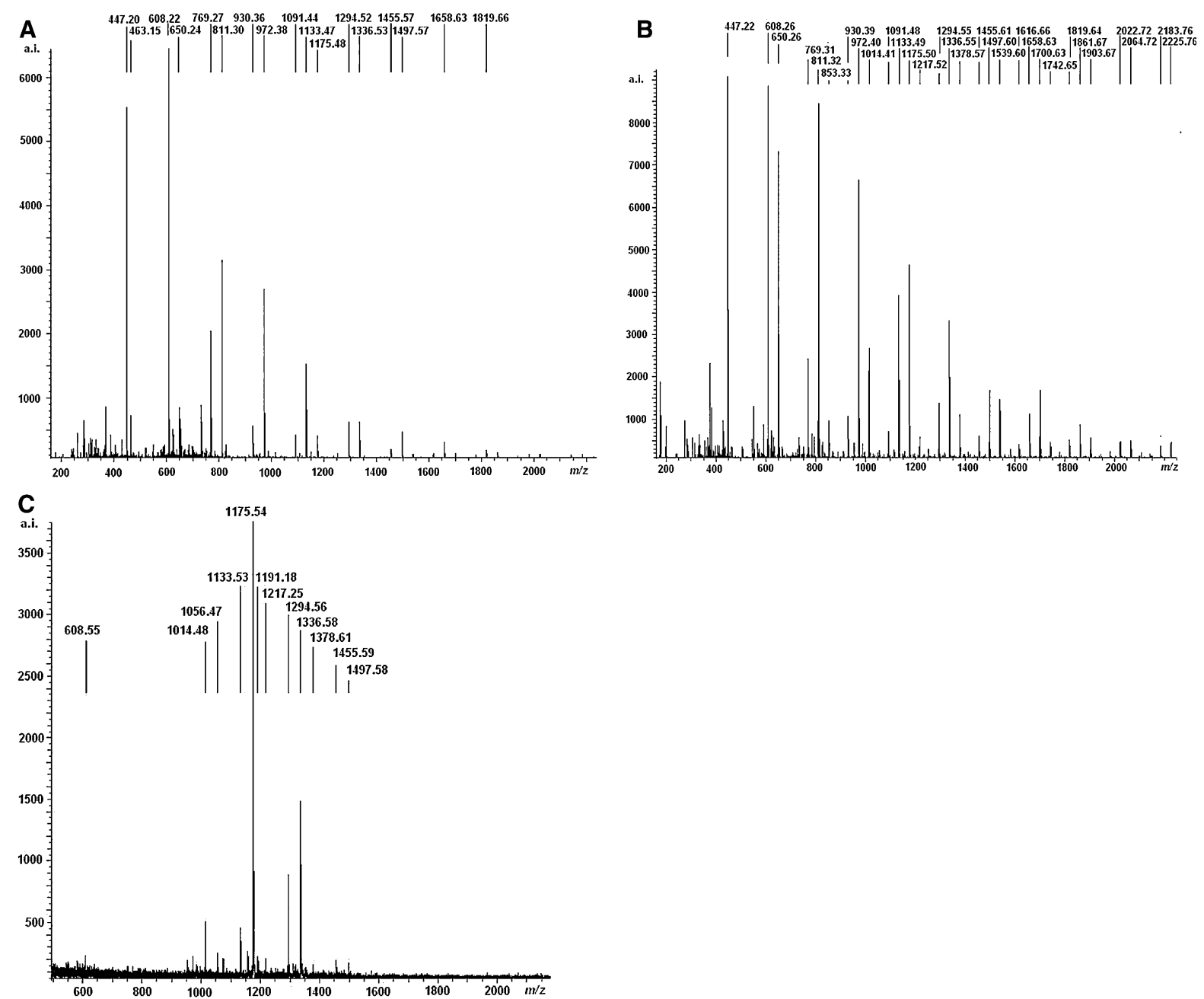

Fig. 1 MALDI TOF MS of chitooligosaccharides: (a) sample Q3, (b) sample Q2, (c) sample Q1

of Q3 (Fig. 2c). The inhibition was even detected after day 3, suggesting that $P$. expansum was not able to degrade the higher oligosaccharide and thus, Q3 continued to act as inhibitors of GR. For Q2 and Q1, the GR values of $P$. expansum were much more similar to those of the control experiments, probably due to a more efficient degradation of the oligosaccharides.

For $R$. stolonifer, concentration dependent inhibitions were observed until $48 \mathrm{~h}$ in assays amended with Q3 or Q2 (Fig. 2d). After $36 \mathrm{~h}$ with Q2 and $48 \mathrm{~h}$ with Q3, the inhibition was gradually reverted. With Q1, however, the GR were similar to those of the control until day 3 and increased thereafter even at the highest concentration, indicating that Q1 acted as a nutrient for $R$. stolonifer.

\section{Investigation of Chitinolytic Activities}

In order to investigate the fate of the chitooligosaccharides in the cultures, the spent media containing an initial concentration of $1,000 \mu \mathrm{g} \times \mathrm{ml}^{-1}$ of the mixture under investigation were analyzed by MALDI TOF MS (Table 3; for mass spectra, see supplement). All fungi were capable of degrading chitooligosaccharides to varying extents. The spent medium of A. alternata amended with Q3 and Q2, contained D3A2 as the highest oligosaccharide whereas those of $\mathrm{DP} \geq 6$ were essentially not detectable. A. alternata also degraded Q1. It is worth noting that the major oligosaccharides detected in the medium had a lower $F_{\mathrm{A}}$ than the original sample, as 
Table 2 Changes in growth A. alternata, B. cinerea and P. expansu $m$ on day six, and $R$. stolonifer on day three in complete medium, amended with chitooligomers.

\begin{tabular}{|c|c|c|c|c|c|}
\hline \multirow{2}{*}{$\begin{array}{l}\text { Oligosaccharide } \\
\text { sample }\end{array}$} & \multirow{2}{*}{$\begin{array}{l}\text { Concentration } \\
\left(\mu \mathrm{g} \times \mathrm{ml}^{-1}\right)\end{array}$} & \multicolumn{4}{|c|}{ Change in growth of fungi $(\%)$} \\
\hline & & A. alternata & B. cinerea & P. expansum & R. stolonifer \\
\hline Control & 0 & $100 \pm 6$ & $100 \pm 17$ & $100 \pm 10$ & $100 \pm 14$ \\
\hline \multirow[t]{3}{*}{ Q3 } & 100 & $+39 \pm 5$ & $-14 \pm 5$ & $-7 \pm 1$ & $+7 \pm 0.3$ \\
\hline & 400 & $-41 \pm 13$ & $-50 \pm 4$ & $-21 \pm 4$ & $+98 \pm 46$ \\
\hline & 1,000 & $+15 \pm 4$ & $-54 \pm 8$ & $-11 \pm 3$ & $+190 \pm 92$ \\
\hline \multirow[t]{3}{*}{ Q2 } & 100 & $-6 \pm 3$ & $+10 \pm 1$ & $+6 \pm 0$ & $+26 \pm 3$ \\
\hline & 400 & $+73 \pm 6$ & $-26 \pm 3$ & $+7 \pm 0.1$ & $-2 \pm 0.4$ \\
\hline & 1,000 & $+83 \pm 20$ & $+7 \pm 1$ & $0 \pm 0$ & $-45 \pm 24$ \\
\hline \multirow[t]{3}{*}{ Q1 } & 100 & $+17 \pm 4$ & $+6 \pm 0.60$ & $+6 \pm 0.1$ & $+45 \pm 8$ \\
\hline & 400 & $+18 \pm 7$ & $+1 \pm 0.2$ & $-2 \pm 0.2$ & $+40 \pm 10$ \\
\hline & 1,000 & $+19 \pm 2$ & $-6 \pm 0.8$ & $-13 \pm 4$ & $+64 \pm 21$ \\
\hline
\end{tabular}

Data are means \pm S.D. $(n=3)$

revealed by comparing the peak intensities of (e.g.) the tetramers or pentamers: D1A3 and D2A3 are present in Q3 but absent in the spent medium where D2A2 and D3A2 are detected as major products. This could indicate that the fungus produces enzymes which catalyze partial deacetylation of the oligomers and/or transglycosidation.

Similar degradation patterns were found with $R$. stolonifer where the growth responses to the three oligosaccharide samples had also been similar to A. alternata.

$P$. expansum which was virtually unaffected by any of the mixtures of oligosaccharides, with respect to their degradation; only D2A1 was detected in the medium containing initially $1,000 \mu \mathrm{g} \times \mathrm{ml}^{-1}$ of Q3, while Q2 had disappeared completely, and Q1 was degraded to A2 with traces of D1A1 and A3 (Table 3). The mass spectrum shows, besides numerous unidentified components, the corresponding sodiated as well as potassiated peaks of $\mathrm{A} 2$ at $\mathrm{m} / \mathrm{z}=447.27 / 463.23$, of D2A1 at $m / z=566.97 / 582.98$, and of A3 at $m / z=650.79 / 666.75 \quad$ (Fig. 3a). Surprisingly, even though $P$. expansum appeared to degrade and consume the oligomers almost completely, no GR increase was observed.

In contrast, $B$. cinerea which is susceptible to inhibition by larger oligomers (i.e. Q3 and Q2) but resistant to smaller ones (i.e. Q1), could not or only poorly degrade the chitooligosaccharides.

MALDI TOF MS of the spent medium showed a different fate of Q1, as compared with Q3 and Q2, containing small oligomers (Fig. 3b and Table 3). Several peaks of sodiated or potassiated ion peaks correspond to oligosaccharides which were not present in the original sample Q1, i.e. $m / z=$ 566.26/582.22 (D2A1), 608.27/624.22 (D1A2), 769.32/785.28 (D2A2), 811.38/827.30 (D1A3), 930.39/946.37 (D3A2), 972.41/988.39 (D2A3), and 1091.47/1107.46 (D4A2). However, the hexamer and the heptamer present in the original sample persisted, as shown by peaks at $\mathrm{m} / \mathrm{z}=1133.51 / 1149.47$ (D3A3), 1175.53/1191.49 (D2A4), 1294.55/1310.53 (D4A3), and 1336.57/1352.54 (D3A4).

In order to complement the work and to verify the presence of chitinolytic enzymes, the spent media was analyzed by the overlay technique over poly-(acrylamide)gels containing either glycol chitin or chitosan as a substrate, as described by Trudel and Asselin [19]. The results shown in Fig. 4 reveal chitosanase activity most prominently with A. alternata, while the hydrolysis of chitosan was lower with $P$. expansum and $R$. stolonifer and virtually absent with $B$. cinerea. On the other hand, significant hydrolysis of glycol-chitin was detected with $P$. expansum only, while chitinase activity in the medium of A. alternata was low, and absent in the media of $R$. stolonifer and B. cinerea. Further studies on this topic will be published elsewhere.

The results lead to the conclusion, that chitooligosaccharides of $\mathrm{DP} \leq 8$ (Q1), are not notably inhibitory to any of the fungi. On the other hand, higher chitooligosaccharides (Q3 and Q2) show 


\section{A Alternaria alternata}

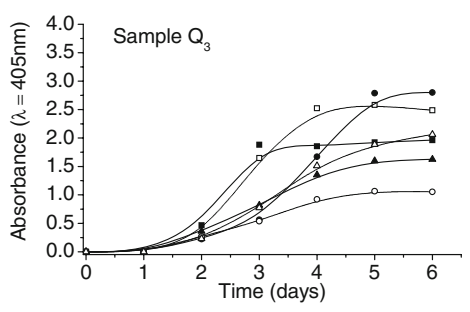

\section{B Botrytis cinerea}

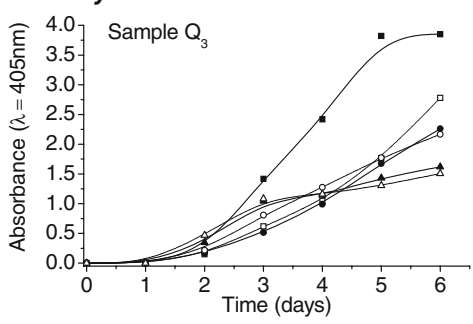

\section{Penicillium expansum}

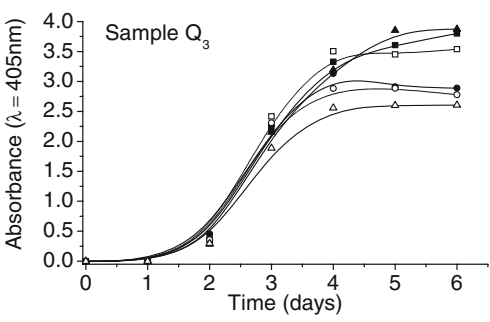

\section{Rhizopus stolonifer}

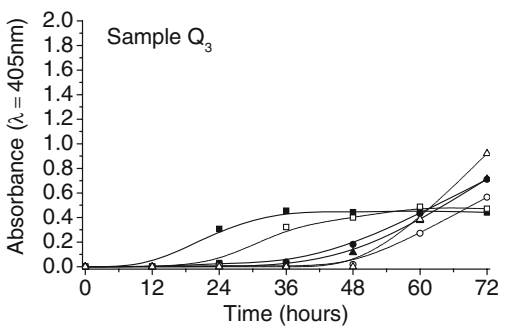

Fig. 2 Growth curves of (a) A. alternata, (b) B. cinerea, (c) $P$. expansum, (d) R. stolonifer in the presence of chitooligosaccharides: $\square$ (control), $\square$ 100, • 200, $\bigcirc 400, \boldsymbol{\Delta} 800, \triangle$
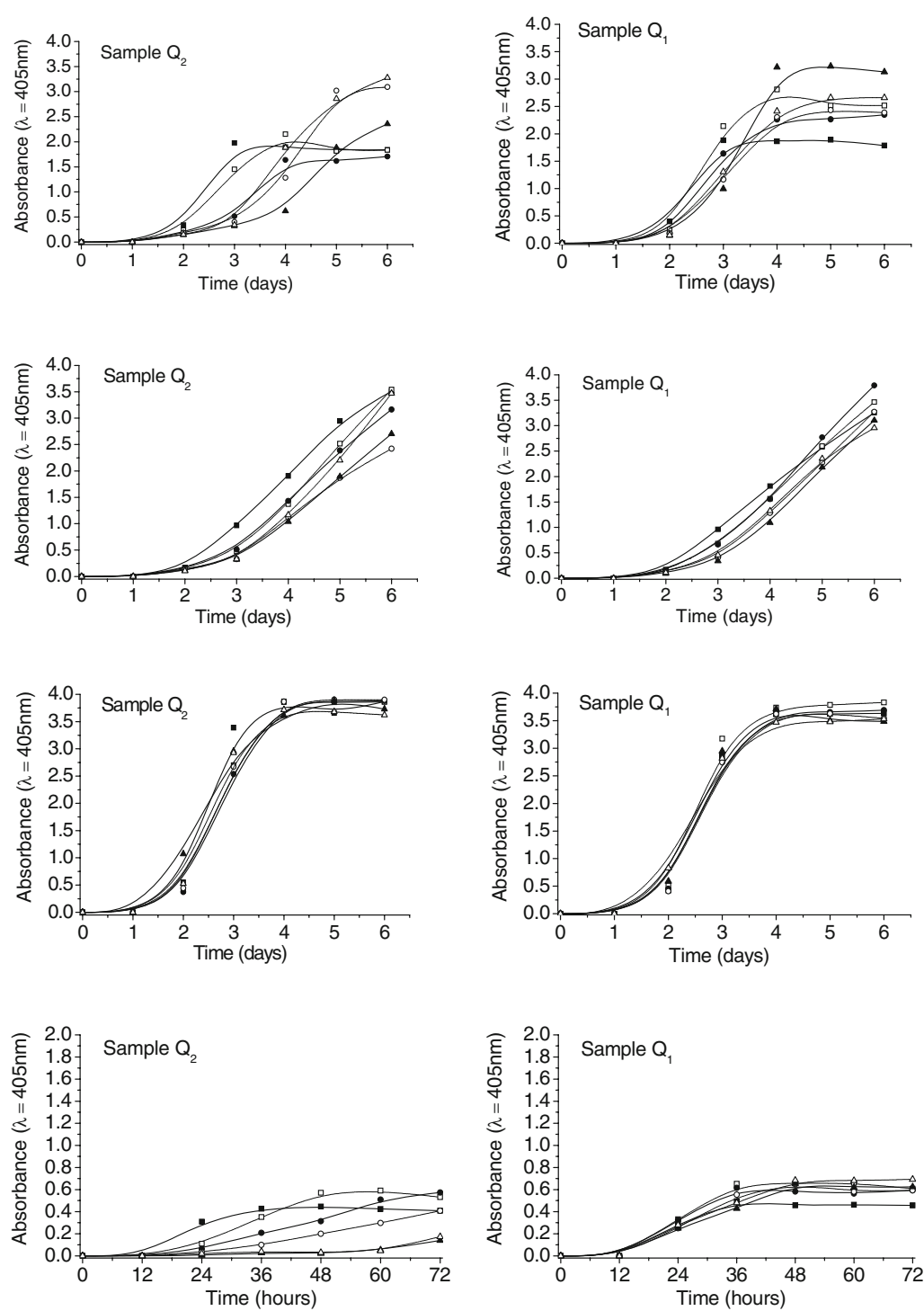

$1,000 \mu \mathrm{g} \times \mathrm{ml}^{-1}$. Data are means of three replicate experiments \pm S.D. For complete data, see ref. [20] initially inhibitory effects which seem to be more pronounced at a lower $F_{\mathrm{A}}$ (i.e. Q3 versus Q2). Reversal of inhibition or even stimulation of growth is probably caused by degradation, resulting in detoxification of the oligosaccharides, as well as in the production of dimers and trimers which apparently act as nutrients for the fungi. This hypothesis is supported by the observation that lack of inhibition or even the stimulation occurs with Q1, which is a fraction of Q2 containing mainly the hexamer D2A4 and the heptamer D3A4.

The exact mechanism by which the higher chitooligosaccharides exert antimicrobial activity is unknown. Based on the other authoŕs observation that the fungistatic activity is higher at lower $\mathrm{pH}$, it was assumed that the toxicity is correlated, besides to 
Table 3 Chitooligosaccharides identified by MALDI TOF MS in spent media of cultures of A. alternata (Aa), B. cinerea (Bc), $P$. expansum $(\boldsymbol{P e})$, and $R$. stolonifer $(\boldsymbol{R s})$ cultured in the presence of chitooligosaccharides

\begin{tabular}{|c|c|c|c|c|c|c|c|c|c|c|c|c|c|c|c|c|}
\hline & & Q3 & $A a$ & $B c$ & $P e$ & $R s$ & Q2 & $A a$ & $B c$ & $P e$ & $R s$ & Q1 & $A a$ & $B c$ & $P e$ & $R s$ \\
\hline \multirow[t]{2}{*}{ DP2 } & D1A1 & & • & & & & & $\bullet$ & $\odot$ & & & & $\bullet$ & & & \\
\hline & A2 & $\bullet$ & & & & $\odot$ & • & & & & $\odot$ & & $\bullet$ & & $\bullet$ & \\
\hline \multirow[t]{3}{*}{ DP3 } & $\mathrm{D} 2 \mathrm{~A} 1$ & & • & & $\bullet$ & $\bullet$ & & $\bullet$ & & & $\odot$ & & $\bullet$ & $\odot$ & $\odot$ & $\odot$ \\
\hline & D1A2 & $\bullet$ & • & $\bullet$ & & $\bullet$ & • & $\bullet$ & • & & $\bullet$ & & $\bullet$ & $\bullet$ & & \\
\hline & A3 & $\odot$ & & & & & • & & & & $\odot$ & & & & $\odot$ & \\
\hline \multirow[t]{5}{*}{ DP4 } & D4 & & & & & & & & & & & & & & & $\odot$ \\
\hline & D3A1 & & $\odot$ & & & $\bullet$ & & & & & • & & & & & \\
\hline & $\mathrm{D} 2 \mathrm{~A} 2$ & $\bullet$ & • & $\bullet$ & & • & $\odot$ & • & $\bullet$ & & • & & • & • & & \\
\hline & D1A3 & • & & $\bullet$ & & $\bullet$ & $\bullet$ & • & • & & & & $\odot$ & $\odot$ & & \\
\hline & A4 & & & & & & $\odot$ & & & & & & & & & \\
\hline \multirow[t]{6}{*}{ DP5 } & D5 & & & & & & & & & & & & & & & \\
\hline & D4A1 & & & & & & & & & & $\odot$ & & & & & $\odot$ \\
\hline & D3A2 & $\odot$ & $\bullet$ & $\odot$ & & $\bullet$ & $\odot$ & $\odot$ & $\odot$ & & $\odot$ & & $\odot$ & $\odot$ & & \\
\hline & $\mathrm{D} 2 \mathrm{~A} 3$ & $\bullet$ & & $\bullet$ & & $\odot$ & $\bullet$ & $\odot$ & $\bullet$ & & & & $\odot$ & $\bullet$ & & \\
\hline & D1A4 & $\odot$ & & & & & $\odot$ & & & & & $\odot$ & & & & \\
\hline & A5 & & & & & & & & & & & $\odot$ & & & & \\
\hline \multirow[t]{6}{*}{ DP6 } & D6 & & $\odot$ & & & & & & & & & & & & & \\
\hline & D5A1 & & & & & & & & & & & & & & & $\odot$ \\
\hline & D4A2 & $\odot$ & & $\odot$ & & $\odot$ & $\odot$ & & $\odot$ & & & & & $\odot$ & & $\odot$ \\
\hline & D3A3 & $\bullet$ & & $\bullet$ & & & • & $\odot$ & • & & & $\odot$ & & $\bullet$ & & \\
\hline & $\mathrm{D} 2 \mathrm{~A} 4$ & $\odot$ & & $\odot$ & & & • & & $\odot$ & & & $\bullet$ & & $\bullet$ & & \\
\hline & D1A5 & & & & & & $\odot$ & & & & & & & & & \\
\hline \multirow[t]{4}{*}{ DP7 } & D5A2 & & & $\odot$ & & & & & & & & & & & & \\
\hline & D4A3 & $\bullet$ & & $\bullet$ & & & $\odot$ & & $\odot$ & & & $\bullet$ & & $\bullet$ & & \\
\hline & D3A4 & $\bullet$ & & $\bullet$ & & & $\bullet$ & & $\odot$ & & & $\bullet$ & & $\bullet$ & & \\
\hline & D2A5 & & & & & & $\odot$ & & & & & & & & & \\
\hline \multirow[t]{4}{*}{ DP8 } & D5A3 & $\odot$ & & $\odot$ & & & $\odot$ & & $\odot$ & & & $\odot$ & & & & \\
\hline & D4A4 & • & & $\odot$ & & & • & & $\odot$ & & & & & & & \\
\hline & D3A5 & $\odot$ & & & & & • & & & & & & & & & \\
\hline & D2A6 & & & & & & $\odot$ & & & & & & & & & \\
\hline \multirow[t]{4}{*}{ DP9 } & D6A3 & & & $\odot$ & & & $\odot$ & & $\odot$ & & & & & & & \\
\hline & D5A4 & $\odot$ & & $\odot$ & & & • & & $\odot$ & & & & & & & \\
\hline & D4A5 & $\odot$ & & & & & • & & $\odot$ & & & & & & & \\
\hline & D3A6 & & & & & & $\odot$ & & & & & & & & & \\
\hline \multirow[t]{5}{*}{ DP10 } & D7A3 & $\odot$ & & $\odot$ & & & $\odot$ & & & & & & & & & \\
\hline & D6A4 & $\odot$ & & $\odot$ & & & $\odot$ & & & & & & & & & \\
\hline & D5A5 & & & $\odot$ & & & $\bullet$ & & & & & & & & & \\
\hline & D4A6 & & & & & & $\odot$ & & & & & & & & & \\
\hline & D3A7 & & & & & & $\odot$ & & & & & & & & & \\
\hline \multirow[t]{3}{*}{ DP11 } & D6A5 & & & & & & $\odot$ & & & & & & & & & \\
\hline & D5A6 & & & $\odot$ & & & $\odot$ & & & & & & & & & \\
\hline & D4A7 & & & & & & $\odot$ & & & & & & & & & \\
\hline \multirow[t]{2}{*}{ DP12 } & D7A5 & & & & & & $\odot$ & & & & & & & & & \\
\hline & D6A6 & & & & & & $\odot$ & & & & & & & & & \\
\hline
\end{tabular}

•: major, $\odot$ : minor components 


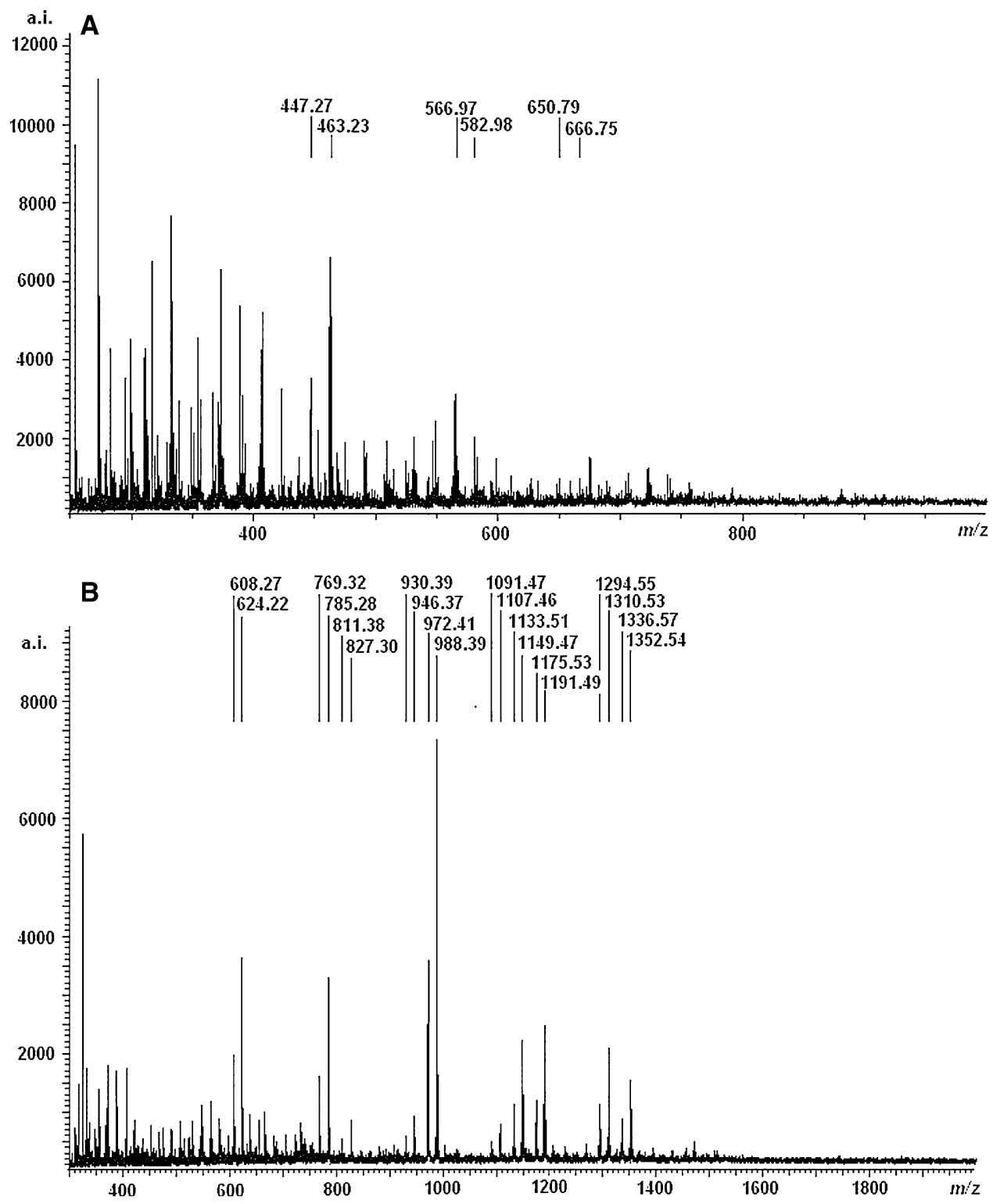

Fig. 3 MALDI TOF MS of the spent medium from (a) P. expansum, (b) B. cinerea, grown for six days in the presence of $1,000 \mu \mathrm{g} / \mathrm{ml}$ of sample Q1

optimum DP, to the cationic charge of the oligosaccharides [15]. Our studies indicate that reasons also can be important for the growth rates inhibition, i.e. enzymatic uptake of simple carbohydrates by permeases could temporally be blocked by the presence of the large oligosaccharides [24]. Several fungi systems however, as cellulase containing, are usually controlled by inducers, and glucose or catabolite repression, and the expression of enzymes to hydrolyze larger molecules to soluble oligosaccharides (low DP). After cellulose and large molecules are degraded a large amount of glucose is liberated, which causes catabolite repression [25]. Chitin hydrolyzing enzymes could be similarly regulated, controlled by inducers and short chain molecules. Amaretti et al [26] have demonstrated carbohydrate preferences in bacteria resulting from different distributions of carbon fluxes through the fermentative 


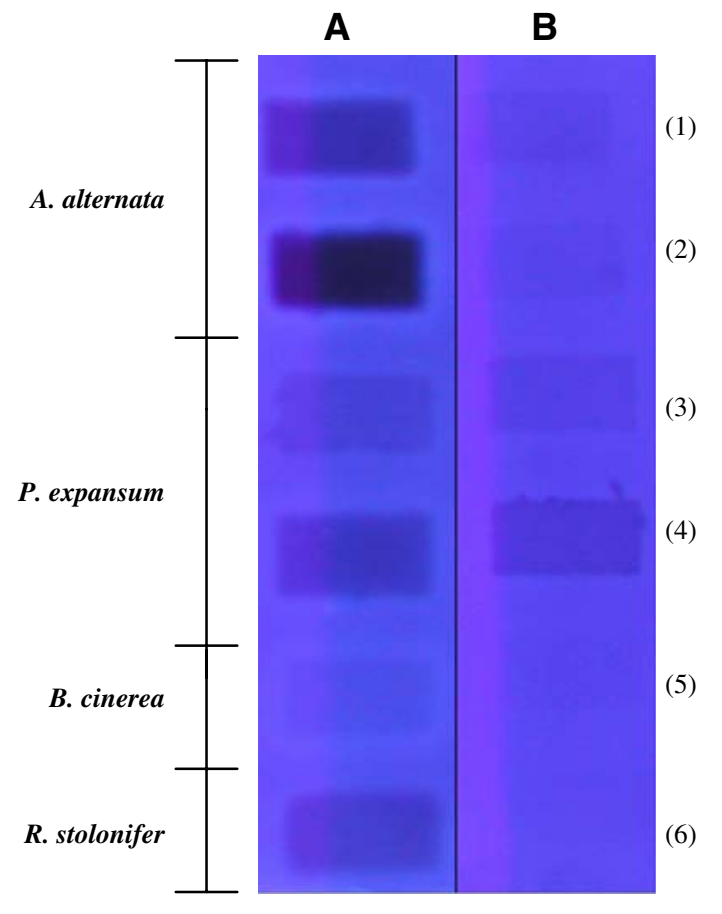

Fig. 4 Detection of chitinolytic enzymes. Lane (a) overlay with glycol chitin containing gel, lane (b) overlay with chitosan $\left(F_{\mathrm{A}} 0.22\right.$; DP1,383) containing gel. Lines 1 and 3 represent desalted spent media, while the samples applied for lines 2, 3, 5 , and 6 were not desalted

pathway, where it was observed substrate selectivity based on the degree of polymerization, when shorter saccharides were the first to be consumed, while a delay was observed until longer oligosaccharides were utilized. This mechanism would well be important for the differential sensitivity of the fungi, i.e. susceptibility or resistance or even stimulation of growth. Further work will be required before generalizations can be made about the relationship between DP of chitosans and chitooligomers, detoxification, and inhibitory activity.

\section{Supplementing Material}

1. Absorption Readings during growth of fungi. 2. Growth curves in color. 3. Mass spectra.

Acknowledgments Financial support by the Brazilian funding agencies FAPESP, CAPES and $\mathrm{CNPq}$ is gratefully acknowledged, as also to the PROBRAL programme (CAPES/ DAAD) and to the European Commission (ALFA Programme, II-0259-FA-FC POLYLIFE).

\section{References}

1. Peter MG. Chitin and chitosan from fungi. In: Steinbüchel A, editor. Biopolymers, vol. 6. Weinheim: Wiley-VCH; 2002. p. 123-57.

2. Peter MG. Chitin and chitosan from animal sources. In: Steinbüchel A, editor. Biopolymers, vol. 6. Weinheim: Wiley-VCH; 2002. p. 481-574.

3. Allan CR, Hadwiger LA. The fungicidal effect of chitosan on fungi of varying cell composition. Exp Mycol. 1979;3:285-7.

4. Uchida Y, Izume M, Ohtakara A. Preparation of chitosan oligomers with purified chitosanase and its application. In: Skjåk-Bræk G, Anthonsen T, Sandford P, editors. Chitin and chitosan: sources, chemistry, biochemistry, physical properties and applications. London: Elsevier; 1988. p. $373-82$.

5. Yalpani M, Johnson F, Robinson LE. Antimicrobial activity of some chitosan derivatives. In: Brine CJ, Sandford PA, Zikakis JP, editors. Advances in chitin and chitosan. London: Elsevier Applied Science; 1992. p. 543-55.

6. El Ghaouth A, Arul J, Ponnampalam R, Boulet M. Chitosan coating effect on storability and quality of fresh strawberries. J Food Sci. 1991;56:1618-31.

7. El Ghaouth A, Arul J, Grenier J, Asselin A. Antifungal activity of chitosan on two postharvest pathogens of strawberry fruits. Phytopathology. 1992;82:398-402.

8. El Ghaouth A, Arul J, Grenier J, Benhamou N, Asselin A, Belanger R. Effect of chitosan on cucumber plants: suppression of Pythium aphanidermatum and induction of defense reactions. Phytopathology. 1994;84:313-20.

9. Jiang YM, Li YB. Effects of chitosan coating on postharvest life and quality of longan fruit. Food Chem. 2001;73:139-43.

10. Bhaskara Reddy MV, Arul J, Angers P, Couture L. Chitosan treatment of wheat seeds induces resistance to Fusarium graminearum and improves seed quality. J Agric Food Chem. 1999;47:1208-16.

11. Bhaskara Reddy MV, Angers P, Castaigne F, Arul J. Chitosan effects on blackmold rot and pathogenic factors produced by Alternaria alternata in postharvest tomatoes. J Am Soc Hortic Sci. 2000;125:742-7.

12. Bhaskara Reddy MV, Belkacemi K, Corcuff R, Castaigne F, Arul J. Effect of pre-harvest chitosan sprays on postharvest infection by Botrytis cinerea and quality of strawberry fruit. Postharvest Biol Technol. 2000;20:39-51.

13. Hirano S, Nagao N. Effects of chitosan, pectic acid, lysozyme and chitinase on the growth of several phytopathogens. Agric Biol Chem. 1989;53:3065-6.

14. Zhang M, Tan TW. Insecticidal and fungicidal activities of chitosan and oligo-chitosan. J Bioact Compat Polym. 2003;18:391-400.

15. Torr KM, Chittenden C, Franich RA, Kreber B. Advances in understanding bioactivity of chitosan and chitosan oligomers against selected wood-inhabiting fungi. Holzforschung. 2005;59:559-67.

16. Kendra DF, Hadwiger LA. Characterization of the smallest chitosan oligomer that is maximally antifungal to Fusarium solani and elicits pisatin formation by Pisum sativum. Exp Mycol. 1984;8:276-81. 
17. Pontecorvo G. The genetics of Aspergillus nidulans. Adv Genet. 1953;5:150-1.

18. Langvad F. A rapid and efficient method for growth measurement of filamentous fungi. J Microbiol Methods. 1999;37:97-100.

19. Trudel J, Asselin A. Detection of chitinase activity after polyacrylamide gel electrophoresis. Anal Biochem. 1989;178:362-6.

20. Bahrke S, Einarsson JM, Gislason J, Haebel S, Letzel MC, Peter-Katalinic J, Peter MG. Sequence analysis of chitooligosaccharides by matrix-assisted laser desorption ionization postsource decay mass spectrometry. Biomacromolecules. 2002; 3:696-704.

21. Haebel S, Bahrke S, Peter MG. Quantitative Sequencing of complex mixtures of heterochitooligosaccharides by vMALDI-Linear ion trap mass spectrometry. Anal Chem. 2007;79:5557-66.

22. Sorbotten A, Horn S J, Eijsink VGH, Varum KM. Degradation of chitosans with chitinase B from Serratia marcescens-production of chito-oligosaccharides and insight into enzyme processivity. FEBS J. 2005;272: 538-49.

23. Vårum KM, Anthonsen MW, Grasdalen $\mathrm{H}$, Smidsrød O. 13C-N.m.r. studies of the acetylation sequences in partially $\mathrm{N}$-deacetylated chitins (chitosans). Carbohydr Res. 1991;217:19-27.

24. Oliveira-Jr. EN. Caracterização dos efeitos de quitosanas na inibição de fungos fitopatogênicos, PhD. thesis, State University of Campinas (UNICAMP), Brazil, 2006. 106pp.

25. Suto M, Tomita F. Induction, catabolite repression mechanisms of cellulase in fungi. $\mathrm{J}$ Biosci Bioeng. 2001;92(4):305-11.

26. Amaretti A, Bernardi T, Tamburini E, Zanoni S, Lomma M, Matteuzzi D, Rossi M. Kinetics and metabolism of Bifidobacterium adolescentis MB 239 growing on glucose, galactose, lactose, and galactooligosaccharides. Appl Environ Microbol. 2007; 11:3637-44. 